\title{
Significance of the hedgehog pathway-associated proteins Gli-1 and Gli-2 and the epithelial-mesenchymal transition-associated proteins Twist and E-cadherin in hepatocellular carcinoma
}

\author{
HYUNG WOOK $\mathrm{CHUN}^{1}$ and RAN HONG ${ }^{2}$ \\ ${ }^{1}$ Department of Medicine, Graduate School; ${ }^{2}$ Department of Pathology, College of Medicine, \\ Chosun University, Gwangju 501-759, Republic of Korea
}

Received March 25, 2015; Accepted June 29, 2016

DOI: $10.3892 / \mathrm{ol} .2016 .4884$

\begin{abstract}
It has been found that abnormal activation of the hedgehog $(\mathrm{Hh})$ signaling pathway is involved in the occurrence, invasion and metastasis of malignant tumors. In addition, epithelial-mesenchymal transition (EMT) also performs an important function in the invasion and metastasis of malignant tumors. However, the significance of the Hh signaling pathway and EMT in hepatocellular carcinoma (HCC) remains unknown. In the present study, the expression of Gli family zinc finger 1 (Gli-1) and Gli family zinc finger 2 (Gli-2), which are key transcriptional factors in the Hh signaling pathway, and Twist and E-cadherin, which are two factors involved in EMT, was examined in 42 patients with HCC and 20 cases of non-tumorous liver (NTL) tissue by immunohistochemistry. Clinicopathological information was collected in order to analyze the correlation of the Hh signaling pathway with EMT. The present study aimed to examine the difference in the expression of Gli-1, Gli-2, E-cadherin and Twist in HCC and NTL to assess the diagnostic value of these factors in HCC. Additionally, the present study aimed to elucidate the correlation between those proteins and other clinicopathological parameters. Whether abnormal activation of the Hh signaling pathway is closely associated with EMT was also evaluated. Gli-1 and Twist expression was found to be significantly increased and E-cadherin expression was found to be decreased in HCC in contrast to NTL (Gli-1, $\mathrm{P}=0.019$; Twist, $\mathrm{P}=0.003$; E-cadherin, $\mathrm{P}<0.001)$. Increased Twist expression was associated with the tumor size $(\mathrm{P}=0.043)$, and loss of or decreased E-cadherin expression was associated with the histological type of HCC
\end{abstract}

Correspondence to: Dr Ran Hong, Department of Pathology, College of Medicine, Chosun University, 375 Seosuk-Dong, Gwangju 501-759, Republic of Korea

E-mail: nanih@chosun.ac.kr

Key words: hedgehog signaling pathway, Gli-1, Twist, E-cadherin, epithelial-mesenchymal transition, hepatocellular carcinoma
$(\mathrm{P}=0.021)$. There was an inverse association between the expression of Twist and E-cadherin $(\mathrm{P}=0.006)$. These results showed that Twist overexpression by induction of EMT changes is involved in the occurrence and progression of HCC. However, the role of Hh signaling pathway-associated proteins in HCC may require elucidation by additional studies using additional materials in the future.

\section{Introduction}

Hepatocellular carcinoma (HCC) is the fifth most common malignancy and the third leading cause of cancer-associated mortality. It is estimated that 500,000-1,000,000 new cases of HCC develop every year $(1,2)$. The disease is often fatal since HCC shows aggressive metastasis and is often diagnosed at an advanced stage (3). Despite advances in surgical and chemotherapeutic approaches, the prognosis of $\mathrm{HCC}$ is poor; the 5-year survival rate of patients with $\mathrm{HCC}$ is as low as 20-50\%, even in early-stage HCC subsequent to radical resection $(4,5)$. Recurrence following treatment remains one of the most important causes of poor long-term survival. Molecular markers for the prediction of prognosis of HCC may be able to aid the development of more effective therapeutic strategies (6).

The hedgehog $(\mathrm{Hh})$ signaling pathway is an important pathway in the development of embryos and is essential for the growth and differentiation of embryonic cells and the maintenance of stem cells (7). However, abnormal activation of this signaling pathway may cause excessive cell proliferation, resulting in the development of cancer (8). Recently, abnormal activation of the Hh pathway has been reported in diverse cancers, including skin, gastrointestinal tract, breast, prostate, pancreas and lung cancer (9-15). The Hh signaling pathway is composed of three ligands, consisting of sonic $\mathrm{Hh}$ (Shh), Indian Hh, and desert Hh, which bind to the transmembrane receptor Patched 1 (Ptch1) (2). The Hh signaling cascade is initiated as $\mathrm{Hh}$ binds to the 12 transmembrane proteins that form Ptch1. This internalizes Ptch1 and relieves the suppression of Smoothened (Smo), which activates the glioma-associated oncogene Gli transcription factor. The Gli transcription factor exists in 3 forms, consisting of GLI family zinc finger 1 (Gli-1), GLI family zinc finger 2 (Gli-2) and GLI family zinc finger 3 (Gli-3) $(11,16)$. 
Although the detailed mechanism of this pathway has yet to be established, it is known that full-length Gli-3 is transported into the nucleus in order to activate the $\mathrm{Hh}$ target genes (17). Among the Hh target genes functioning as transactivators, Gli-1 is considered to be a marker of the Hh pathway activation $(17,18)$. In addition, the Hh pathway cascade cross-talks with the WNT, epidermal growth factor (EGF)/fibroblast growth factor (FGF) and transforming growth factor (TGF)- $\beta /$ Activin/Nodal/bone morphogenetic protein (BMP) signaling cascades, which are implicated in epithelial-to-mesenchymal transition (EMT) through repression of E-cadherin and activation of N-cadherin. Therefore, the Hh signaling pathway is involved in the invasion and metastasis of cancers (19). EMT also plays an important role in the invasion and metastasis of cancers. Epithelial cells lose cell polarity and cell-cell adhesion properties, and gain migratory and invasive properties to become mesenchymal cells during the process of EMT (20). Cells that have undergone EMT behave similarly to stem cells isolated from normal or neoplastic cell populations in numerous ways (21). The basic helix-loop-helix transcription factor Twist and the zinc-finger transcriptional repressor Snail are important regulators of EMT. These transcription factors induce changes in the spreading ability and morphology of cancer cells through suppression of E-cadherin expression, and epithelial cancer cells then acquire mesenchymal markers (22). The Hh signaling pathway may be one of the signaling pathways in the tumor microenvironment that involves EMT (23). However, the association between the Hh signaling pathway and EMT in HCC is remains poorly understood.

In the present study, the expression of Gli-1 and Gli-2, which are key transcriptional factors in the Hh signaling pathway, and of Twist and E-cadherin, which are two factors involved in EMT, was evaluated in patients with HCC, according to immunohistochemical results. In addition, the association between the expression of these factors and known clinicopathological factors associated with prognosis was analyzed. The present findings may uncover the clinical significance of the Hh signaling pathway and EMT in HCC.

\section{Materials and methods}

Samples. In total, 42 samples of HCC tissue were obtained from surgical resection, including lobectomy and segmentectomy, performed at the Department of Surgery, Chosun University Hospital (Gwangju, South Korea) between February 2006 and December 2012. The Institutional Review Board of Chosun University Hospital waived the requirement for written informed consent due to the nature of the study (CHOSUN 2014-04-003). For the comparative analysis, 20 samples of non-tumorous liver (NTL) tissue were included.

Histopathological analysis. Each case was re-evaluated by retrospective analysis of the medical records and the tissue slide files at the Department of Pathology, College of Medicine, Chosun University (Gwangju, South Korea). The age, gender, presence of hepatitis B surface antigen (HBsAg) and level of serum $\alpha$-fetoprotein (s-AFP) were assessed. The examined tissues were fixed in $10 \%$ neutral formalin and the prepared paraffin-embedded tissues were sectioned (4-5 $\mu$ m in thickness).
Hematoxylin and eosin (H\&E) staining (Ventana Medical Systems, Tucson, AZ, USA) was performed according to the standard procedure and the sections were examined under a light microscope (Olympus BX51; Olympus Corporation, Tokyo, Japan). By review of the H\&E slides, the histological diagnosis, tumor size, T stage, Edmonson-Steiner grade (24), invasion of liver capsule and bile duct and liver cirrhosis in the non-tumor liver tissue were reevaluated. A representative area of tumor suitable for the purpose of the present study was selected, and the slides were prepared for immunohistochemical analysis.

Immunohistochemical staining. All specimens were tested using rabbit polyclonal anti-Gli-1 (catalog no., ab92611; Abcam, Cambridge, MA, USA), anti-Gli-2 (catalog no., ab7181) and anti-Twist (catalog no., ab50581; Abcam), and mouse monoclonal anti-E-cadherin (catalog no., NCL-L-E-Cad; Novocastra; Leica Biosystems, Milton Keynes, UK) antibodies, according to the manufacturer's protocol. Immunolocalization was performed using the ImmunoCruz Mouse Staining System (catalog no., sc-2050; Santa Cruz Biotechnology, Inc., Dallas, TX, USA), according to the manufacturer's protocol. The staining process was performed according to the protocol recommended by the manufacturer of the NexES autoimmunostainer (Ventana Medical Systems).

Briefly, the 4- $\mu \mathrm{m}$ sections obtained following formalin fixation and paraffin embedding were deparaffinized in xylene and then rehydrated with distilled water through a graded series of ethanol solutions. The sections were then placed in a glass jar with $10 \mathrm{mmol} / \mathrm{l}$ citrate buffer $(\mathrm{pH} 6.0)$ and were irradiated in a microwave oven for $15 \mathrm{~min}$ at $99^{\circ} \mathrm{C}$. The sections were allowed to cool in the jar at room temperature for $20 \mathrm{~min}$. The slides were then rinsed with Tris-buffered saline and, subsequent to quenching the endogenous peroxidase activity in $0.3 \%$ hydrogen peroxide for $10 \mathrm{~min}$. The slides were then washed as described, and immunohistochemistry was performed using the NexES autoimmunostainer. Slides were incubated with primary antibodies against Gli-1 (dilution, 1:100), Gli-2 (dilution, 1:100), Twist (dilution, 1:100) and E-cadherin (dilution, 1:100) for $32 \mathrm{~min}$. The ultraView Universal DAB Detection kit (catalog no., 760-500; Ventana Medical Systems) was used as the secondary detection method. This kit includes the biotinylated immunoglobulin (Ig) secondary purified goat anti-mouse $\operatorname{IgG}$ and IgM and goat anti-rabbit IgG antibodies in phosphate-buffered saline with preservative. Incubation was performed for $8 \mathrm{~min}$ and was followed by the addition of conjugated streptavidin horseradish peroxidase for $8 \mathrm{~min}$. Slides were then counterstained with hematoxylin (catalog no., 760-2021; Ventana Medical Systems).

Analysis and interpretation of staining. Representative histological sections of the lesions were immunohistochemically stained and the expression of the target proteins was analyzed using antibodies against Gli-1, Gli-2, Twist and E-cadherin.

To assess the expression of Gli-1 and Gli-2, a total of 10 high-power fields were selected from each section, and nuclear protein expression in $\geq 10 \%$ of cells was considered to 
Table I. Clinicopathological characteristics of patients with hepatocellular carcinoma.

\begin{tabular}{|c|c|}
\hline Characteristic & Value, n (\%) \\
\hline \multicolumn{2}{|l|}{ Gender } \\
\hline Male & $35(83.3)$ \\
\hline Female & $7(16.7)$ \\
\hline \multicolumn{2}{|l|}{ Age } \\
\hline Mean, years & 57.8 \\
\hline$<50$ years & $5(11.9)$ \\
\hline$\geq 50$ years & $37(88.1)$ \\
\hline \multicolumn{2}{|l|}{$\mathrm{HBsAg}$} \\
\hline Present & $26(61.9)$ \\
\hline Absent & $16(38.1)$ \\
\hline \multicolumn{2}{|l|}{ Tumor size } \\
\hline$<5 \mathrm{~cm}$ & $29(69.0)$ \\
\hline$\geq 5 \mathrm{~cm}$ & $13(31.0)$ \\
\hline \multicolumn{2}{|l|}{$\mathrm{pT}$} \\
\hline 1 & $31(73.8)$ \\
\hline 2 & $5(11.9)$ \\
\hline 3 & $6(14.3)$ \\
\hline \multicolumn{2}{|l|}{ Cirrhosis } \\
\hline Present & $33(78.6)$ \\
\hline Absent & $9(21.4)$ \\
\hline \multicolumn{2}{|l|}{ E-S grade } \\
\hline 1 & $8(19.0)$ \\
\hline 2 & $32(76.2)$ \\
\hline 3 & $2(4.8)$ \\
\hline \multicolumn{2}{|c|}{ Capsule invasion } \\
\hline Present & $8(19.0)$ \\
\hline Absent & $34(81.0)$ \\
\hline \multicolumn{2}{|c|}{ Bile duct invasion } \\
\hline Present & $3(7.1)$ \\
\hline Absent & $39(92.9)$ \\
\hline \multicolumn{2}{|l|}{ Histology } \\
\hline Trabecular & $20(47.6)$ \\
\hline Mixed $^{\mathrm{a}}$ & $18(42.9)$ \\
\hline Solid & $4(9.5)$ \\
\hline \multicolumn{2}{|l|}{ s-AFP } \\
\hline$<100 \mathrm{ng} / \mathrm{ml}$ & $31(73.8)$ \\
\hline$\geq 100 \mathrm{ng} / \mathrm{ml}$ & $11(26.2)$ \\
\hline
\end{tabular}

amixed form composed of pseudoglandular, trabecular and pseudograndular pattern. HBsAg, hepatitis B surface antigen; pT, pathological tumor stage; E-S, Edmonson-Steiner; s-AFP, serum $\alpha$-fetoprotein.

indicate positive expression (23). E-cadherin was expressed in the cellular membrane of normal hepatocytes and cancer cells. Expression intensity that was similar or increased relative to that of adjacent normal hepatocytes was defined as maintenance of expression; weak expression compared with normal hepatocytes or loss of expression was defined as a decrease in expression (25). Twist was expressed in the nucleus and cytoplasm of cancer cells; positive expression was defined as a staining intensity higher than that of background staining.

Statistical analysis. Statistical analysis was performed using SPSS 12.0 software (SPSS, Inc., Chicago, IL, USA). The $\chi^{2}$ test and Fisher's exact test were used to demonstrate the association between the expression of proteins and clinicopathological factors. $\mathrm{P}<0.05$ was considered to indicate a statistically significant difference.

\section{Results}

Clinical and histological features. The clinicopathological characteristics of the patients are summarized in Table I. The mean age of the 42 patients with $\mathrm{HCC}$ at the time of surgery was 57.8 years, and the ratio of male to female patients was $35: 7(83.3: 16.7 \%)$, showing a male predominance. In total, 26 patients $(61.9 \%)$ showed expression of HbsAg. The tumor size was $<5 \mathrm{~cm}$ in 29 patients $(69.0 \%)$ and $\geq 5 \mathrm{~cm}$ in 13 patients $(31.0 \%)$. There were prominent cirrhotic lesions of the background liver in 33 patients with HCC (78.6\%). The $\mathrm{T}$ stage, which was assessed according to tumor size, tumor number and vascular invasion, was classified as pT1 in 31 patients $(73.8 \%)$, pT2 in 5 patients $(11.9 \%)$ and pT3 in 6 patients $(14.3 \%)$. Capsular invasion was found in 8 patients $(19.0 \%)$ and bile duct invasion was found in 3 patients $(7.1 \%)$.

Histologically, tumors were trabecular type in 20 patients (47.6\%), pseudoglandular or mixed type of trabecular and pseudoglandular types in 18 patients $(42.9 \%)$, and solid type in 4 patients $(9.5 \%)$. The s-AFP level was $<100 \mathrm{ng} / \mathrm{ml}$ in 31 patients $(73.8 \%)$ and $\geq 100 \mathrm{ng} / \mathrm{ml}$ in 11 patients $(26.2 \%)$.

Immunohistochemistry results. The present study examined the expression of the $\mathrm{Hh}$ signaling pathway-associated proteins Gli-1 and Gli-2 and the EMT-associated proteins Twist and E-cadherin in 42 tissue samples with HCC and 20 tissue samples of NTL.

The expression of Gli-1 was identified in 2 NTL tissues (10.0\%) and 17 HCC tissues (40.5\%), which showed a statistically significant difference in expression between NTL and HCC ( $\mathrm{P}=0.0 .19)$ (Fig. 1A and B). However, Gli-2 expression was identified in 14 NTL tissues $(70.0 \%)$ and 33 HCC tissues $(78.6 \%)$, which did not show any difference between two groups (Fig. 1C and D).

Strong E-cadherin expression was identified in all NTL tissues (100\%), whereas only $8 \mathrm{HCC}$ tissues were positive for E-cadherin expression, which showed a statistically significant difference between the two groups $(\mathrm{P}<0.001)$ (Fig. 2). Twist expression was also significantly different between the two groups, with Twist expression identified in 8 NTL tissues $(40.0 \%)$ and 34 HCC tissues (81.0\%) $(\mathrm{P}=0.003$; Table II; Fig. 3).

Association between E-cadherin expression and clinicopathological factors. Loss or decrease of E-cadherin expression was identified in 33 out of 42 patients $(78.6 \%)$ with $\mathrm{HCC}$, which was associated with the histological type of HCC, as loss or decrease of expression was identified 
Table II. Expresion of Gli-1, Gli-2, Twist and E-cadherin in NTL and HCC tissues.

\begin{tabular}{lccr}
\hline Protein & NTL, n $(\%)$ & HCC, n $(\%)$ & P-value \\
\hline Gli-1 & & & 0.019 \\
Total & $20(100.0)$ & $42(100.0)$ & \\
+ & $2(10.0)$ & $17(40.5)$ & \\
- & $18(90.0)$ & $25(59.5)$ & \\
Gli-2 & & & 0.532 \\
Total & $20(100.0)$ & $42(100.0)$ & \\
+ & $14(70.0)$ & $33(78.6)$ & \\
- & $6(30.0)$ & $9(21.4)$ & \\
Twist & & & \\
Total & $20(100.0)$ & $42(100.0)$ & \\
+ & $8(40.0)$ & $34(81.0)$ & \\
- & $12(60.00)$ & $8(19.0)$ & \\
E-cadherin & & & \\
Total & $20(100.0)$ & $42(100.0)$ & \\
+ & $20(100.0)$ & $8(19.0)$ & \\
- & $0(0.0)$ & $34(810.0)$ & \\
\hline
\end{tabular}

NTL, non-tumorous liver; HCC, hepatocellular carcinoma; Gli-1, GLI family zinc finger 1; Gli-2, GLI family zinc finger 2 .

in $12 / 20$ trabecular type tissues (60\%), 17/18 mixed type tissues (94.4\%) and 4/4 solid type tissues (100\%). E-cadherin expression demonstrated a significant association with histological differentiation of HCC $(\mathrm{P}=0.021)$ (Fig. 2). However, other clinicopathological factors were not associated with E-cadherin expression (Table III).

Association between Twist expression and clinicopathological factors. Twist expression was identified in 34/42 HCC tissues $(81.0 \%)$ and was associated with tumor size, as Twist expression was identified in $21 / 29$ tumors $<5 \mathrm{~cm}$ in size $(72.4 \%)$ and in $13 / 13$ tumors $\geq 5 \mathrm{~cm}$ in size $(100 \%)(\mathrm{P}=0.043)$. However, other clinicopathological factors were not significantly associated with E-cadherin expression (Table III).

Association between the expression of Gli-1 and Gli-2 and clinicopathological factors. Gli-1 expression and Gli-2 expression did not show a significant association with any clinicopathological factors (Table IV).

Correlation between E-cadherin expression and Twist expression. A significant inverse association was identified between Twist and E-cadherin expression $(\mathrm{P}=0.006)$, as $34 / 42$ HCC tissues $(81.0 \%)$ showed Twist expression, and $30 / 34$ of these Twist-positive HCC tissues showed a loss of or prominent decrease in E-cadherin expression (Table V).

Association between the Hh signaling pathway-associated proteins Gli-1 and Gli-2 and the EMT-associated proteins Twist and E-cadherin. There was no significant association between the expression of the Hh signaling pathway-associated proteins and the EMT-associated proteins.

\section{Discussion}

The Hh signaling pathway plays an important role in embryonic development, organ maturation and morphological maintenance (26). This pathway is inactivated when embryos become mature. Abnormal activation of the Hh signaling pathway is closely associated with the occurrence, invasion and metastasis of certain malignant tumors, including gastric cancer $(19,20)$. Out of several Hh target genes, Gli-1 is a major transcription factor of the Hh signaling pathway (6). High expression of Gli-1 has been reported in several cancers, including gastric and colon cancer, in contrast to normal cells $(6,23)$. Wang et al (23) reported that Gli-1 expression increased markedly in progressive gastric cancer and was closely associated with increased Snail (EMT marker) expression and decreased E-cadherin expression. The positive Gli-1 expression group had a significantly increased invasion depth and a higher percentage of patients with lymph node (LN) invasion compared with the negative Gli-1 expression group. In the study of colon cancer and melanosis coli by Wang et al (27), it was also reported that the protein and mRNA levels of Gli-1 are aberrantly elevated in colon cancer compared with normal tissues.

Gli-2 is one of the transcription factors of the Hh pathway and regulates the expression of downstream target genes, including Gli-1, Bcl-2, c-FLIP, cyclin D1, c-Myc and vascular endothelial growth factor $(6,28,29)$. Gli-2 overexpression has also been reported in several malignant tumors, such as medulloblastoma, breast cancer and $\operatorname{HCC}(6,30)$, and Gli-2 overexpression is associated with poor survival (6).

Im et al (30) analyzed the expression of Hh signaling proteins, including Shh, Ptch, Smo, Gli-1, Gli-2 and Gli-3. The expression of Hh signaling proteins demonstrated a statistically significant correlation with certain prognostic factors, such as LN metastasis and tumor stage. LN metastasis was associated with Shh and Ptch expression and tumor stage was associated with Shh and Gli-3 expression. Gli-2 expression was associated with a poorer overall survival time. In addition, in a study of 68 cases of HCC and 20 cases of NTL by Zhang et al (6), high expression of Gil-2 was identified in HCC tissue and was associated with poor prognostic factors, including differentiation of cancer cells, capsular invasion, tumor recurrence and intra-hepatic metastasis subsequent to hepatectomy.

EMT, which is one of the characteristics of the tumor microenvironment, also plays an important role in the invasion and metastasis of cancers. Through EMT, epithelial cells lose cell polarity and adhesion properties between epithelial cells, and gain migratory and invasive properties to become mesenchymal cells (20). A hallmark of EMT is downregulation of the cell adhesion molecule E-cadherin. E-cadherin is a transmembrane protein that is essential for the formation of adherent cell junctions and the upregulation of mesenchymal molecules, including vimentin, fibronectin and $\mathrm{N}$-cadherin. It has been reported that suppression of E-cadherin is associated with dedifferentiation of cancer cells, infiltrative growth of tumors and the high incidence of LN metastasis in several cancers (31-33). This suppression is induced by several routes, including gene mutation, promoter hypermethylation or promoter repression by transcription repressors 
Table III. Association between expression of Twist and E-cadherin and clinicopathological features of hepatocellular carcinoma.

\begin{tabular}{|c|c|c|c|c|c|c|c|}
\hline \multirow[b]{2}{*}{ Characteristic } & \multirow[b]{2}{*}{ Total, n (\%) } & \multicolumn{3}{|c|}{ E-cadherin, $\mathrm{n}$} & \multicolumn{3}{|c|}{ Twist, $\mathrm{n}$} \\
\hline & & + & - & P-value & + & - & P-value \\
\hline HBsAg & & & & 0.265 & & & 1.000 \\
\hline Present & $26(61.9)$ & 4 & 22 & & 21 & 5 & \\
\hline Absent & $16(38.1)$ & 5 & 11 & & 13 & 3 & \\
\hline Tumor size & & & & 0.232 & & & $0.043^{\mathrm{b}}$ \\
\hline$<50 \mathrm{~mm}$ & $29(69.0)$ & 8 & 21 & & 21 & 8 & \\
\hline$\geq 50 \mathrm{~mm}$ & $13(31.0)$ & 1 & 12 & & 13 & 0 & \\
\hline $\mathrm{pT}$ & & & & 0.660 & & & 0.655 \\
\hline 1 & $31(73.8)$ & 6 & 26 & & 25 & 7 & \\
\hline $2^{\mathrm{a}}$ & $11(26.2)$ & 3 & 7 & & 9 & 1 & \\
\hline Cirrhosis & & & & 1.000 & & & 0.168 \\
\hline Present & $33(78.6)$ & 7 & 26 & & 25 & 8 & \\
\hline Absent & $9(21.4)$ & 2 & 7 & & 9 & 0 & \\
\hline E-S grade & & & & 0.558 & & & 0.651 \\
\hline 1 & $8(19.0)$ & 1 & 7 & & 7 & 1 & \\
\hline 2 & $32(76.2)$ & 8 & 24 & & 25 & 7 & \\
\hline 3 & $2(4.8)$ & 0 & 2 & & 2 & 0 & \\
\hline Capsule invasion & & & & 1.000 & & & 0.635 \\
\hline Present & $8(19.0)$ & 2 & 6 & & 6 & 2 & \\
\hline Absent & $34(81.0)$ & 7 & 27 & & 26 & 8 & \\
\hline Bile duct invasion & & & & 0.525 & & & 1.000 \\
\hline Present & $3(7.1)$ & 1 & 2 & & 3 & 0 & \\
\hline Absent & $39(92.9)$ & 8 & 31 & & 31 & 8 & \\
\hline Histology & & & & $0.021^{\mathrm{b}}$ & & & 0.297 \\
\hline Trabecular & $20(47.6)$ & 8 & 12 & & 14 & 6 & \\
\hline Mixed $^{\mathrm{b}}$ & $18(42.9)$ & 1 & 17 & & 16 & 2 & \\
\hline Solid & $4(9.5)$ & 0 & 4 & & 4 & 0 & \\
\hline s-AFP & & & & 0.403 & & & 0.657 \\
\hline$<100 \mathrm{ng} / \mathrm{ml}$ & $31(73.8)$ & 8 & 23 & & 24 & 7 & \\
\hline$\geq 100 \mathrm{ng} / \mathrm{ml}$ & $11(26.2)$ & 1 & 10 & & 10 & 1 & \\
\hline
\end{tabular}

${ }^{\mathrm{a}} \mathrm{pT} 2+\mathrm{pT} 3 ;{ }^{\mathrm{b}}$ mixed form composed of pseudoglandular, trabecular and pseudograndular patterns, statistically significant. HBsAg, hepatitis B surface antigen; pT, pathological tumor stage; E-S grade, Edmonson-Steiner grade; s-AFP, serum $\alpha$-fetoprotein.

during tumor progression. A variety of transcription factors all interact with the E-box element within the proximal region of the E-cadherin promoter, including the zinc finger Snail homologs Snail1, Snail2/Slug and Snail3, and several basic helix-loop-helix factors, such as Twist, ZEB-1 and ZEB-2 (32,34-36). Of these crucial factors regulating EMT, the Twist family shares homology in structure across the basic helix-loop-helix domain and is expressed during mesoderm and muscle development (37). Similar to other EMT-associated transcription factors, such as Snail, Slug and SIP, Twist binds to DNA using similar E-box sequence motifs and suppresses E-cadherin expression (38).

In the present study, the expression of the Hh-associated proteins Gli-1 and Gli-2 and the EMT-associated proteins Twist and E-cadherin were examined in $42 \mathrm{HCC}$ tissues and $20 \mathrm{NTL}$ tissues by immunohistochemistry, in order to determine the role of the Hh signaling pathway and EMT in HCC. Based on the results of immunohistochemistry, the present study analyzed whether these proteins show different expression in HCC compared with NTL, the association between the expression of these proteins and various clinicopathological factors, and whether the expression of Hh signaling pathway-associated proteins is associated with the expression of EMT-associated proteins in HCC.

In contrast to the results of the study by Zhang et al (6), Gli-2 was expressed in NTL and HCC tissues in the present study, and there was no significant difference between the expression in the two groups. However, Gli-1 was expressed in $40.5 \%$ of HCC tissues and $10 \%$ of NTL tissues, showing a significant difference between the two groups. This finding suggests that Gli-1 expression has diagnostic value for HCC. Gli-1 and Gli-2 expression were not associated with various clinicopathological 
Table IV. Association between the expression of Gli-1 and Gli-2 and clinicopathological features of hepatocellular carcinoma.

\begin{tabular}{|c|c|c|c|c|c|c|c|}
\hline \multirow[b]{2}{*}{ Characteristic } & \multirow[b]{2}{*}{ Total, n (\%) } & \multicolumn{3}{|c|}{ Gli-1, n } & \multicolumn{3}{|c|}{ Gli-2, n } \\
\hline & & + & - & $\mathrm{P}$-value & + & - & P-value \\
\hline HBsAg & & & & 0.195 & & & 0.202 \\
\hline Present & $26(61.9)$ & 13 & 13 & & 22 & 4 & \\
\hline Absent & $16(38.1)$ & 4 & 12 & & 11 & 5 & \\
\hline Tumor size & & & & 0.738 & & & 0.421 \\
\hline$<50 \mathrm{~mm}$ & $29(69.0)$ & 11 & 18 & & 22 & 4 & \\
\hline$\geq 50 \mathrm{~mm}$ & $13(31.0)$ & 6 & 7 & & 11 & 2 & \\
\hline pT & & & & 0.714 & & & 1.000 \\
\hline 1 & $31(73.8)$ & 12 & 20 & & 25 & 7 & \\
\hline $2^{\mathrm{a}}$ & $11(26.2)$ & 5 & 5 & & 8 & 2 & \\
\hline Cirrhosis & & & & 0.446 & & & 0.375 \\
\hline Present & $33(78.6)$ & 12 & 21 & & 27 & 6 & \\
\hline Absent & $9(21.4)$ & 5 & 4 & & 6 & 3 & \\
\hline E-S grade & & & & 0.603 & & & 0.443 \\
\hline 1 & $8(19.0)$ & 2 & 6 & & 7 & 1 & \\
\hline 2 & $32(76.2)$ & 14 & 18 & & 24 & 8 & \\
\hline 3 & $2(4.8)$ & 1 & 1 & & 2 & 0 & \\
\hline Capsule invasion & & & & 1.0 & & & 0.336 \\
\hline Present & $8(19.0)$ & 3 & 5 & & 5 & 3 & \\
\hline Absent & $34(81.0)$ & 14 & 20 & & 28 & 6 & \\
\hline Bile duct invasion & & & & 0.260 & & & 1.000 \\
\hline Present & $3(7.1)$ & 0 & 3 & & 3 & 0 & \\
\hline Absent & 39 (92.9) & 17 & 22 & & 30 & 9 & \\
\hline Histology & & & & 0.704 & & & 0.462 \\
\hline Trabecular & $20(47.6)$ & 9 & 11 & & 16 & 4 & \\
\hline Mixed $^{b}$ & $18(42.9)$ & 6 & 12 & & 13 & 5 & \\
\hline Solid & $4(9.5)$ & 2 & 2 & & 4 & 0 & \\
\hline s-AFP & & & & 0.268 & & & 0.209 \\
\hline$<100 \mathrm{ng} / \mathrm{ml}$ & $31(73.8)$ & 11 & 20 & & 26 & 5 & \\
\hline$\geq 100 \mathrm{ng} / \mathrm{ml}$ & $12(26.2)$ & 6 & 5 & & 7 & 4 & \\
\hline
\end{tabular}

${ }^{\mathrm{a}} \mathrm{pT} 2+\mathrm{pT} 3,{ }^{\mathrm{b}}$ mixed form composed of pseudoglandular, trabecular and pseudograndular patterns. HBsAg, hepatitis B surface antigen; pT, pathological tumor stage; E-S grade, Edmonson-Steiner grade; s-AFP, serum $\alpha$-fetoprotein; Gli-1, GLI family zinc finger 1; Gli-2, GLI family zinc finger 2 .

Table V. Association between Twist and E-cadherin expression in hepatocellular carcinoma tissues.

\begin{tabular}{llrr}
\hline & \multicolumn{2}{c}{ E-cadherin, $\mathrm{n}(\%)$} & \\
\cline { 2 - 3 } Twist & + & - & P-value \\
\hline+ & $4(9.6)$ & $30(71.4)$ & 0.006 \\
- & $5(11.9)$ & $3(7.1)$ & \\
\hline
\end{tabular}

factors. The EMT-associated proteins E-cadherin and Twist showed significantly decreased expression in HCC compared with NTL. E-cadherin was expressed at the cellular membrane in all NTL tissues (100\%). However, 34/42 HCC tissues $(81.0 \%)$ showed a total loss or prominent decrease in E-cadherin expression, which was a statistically significant difference $(\mathrm{P}<0.0001)$. Twist was expressed in $8 / 20$ NTL tissues $(40.0 \%)$ and $34 / 40$ HCC tissues (81.0\%), showing significantly different expression between the two groups. These results suggest that E-cadherin and Twist also have crucial diagnostic value in the histological examination of suspected HCC. Among the various clinicopathological factors assessed, E-cadherin expression was associated with the histological type of HCC, and Twist was associated with the tumor size.

In the study by Katoh et al (19), it was found that the Hh signaling cascade cross-talks with the WNT, EGF/FGF and TGF- $\beta$ /Activin/Nodal/BMP signaling cascades, which are involved in EMT through E-cadherin suppression. The present study examined the association between the Hh signaling 

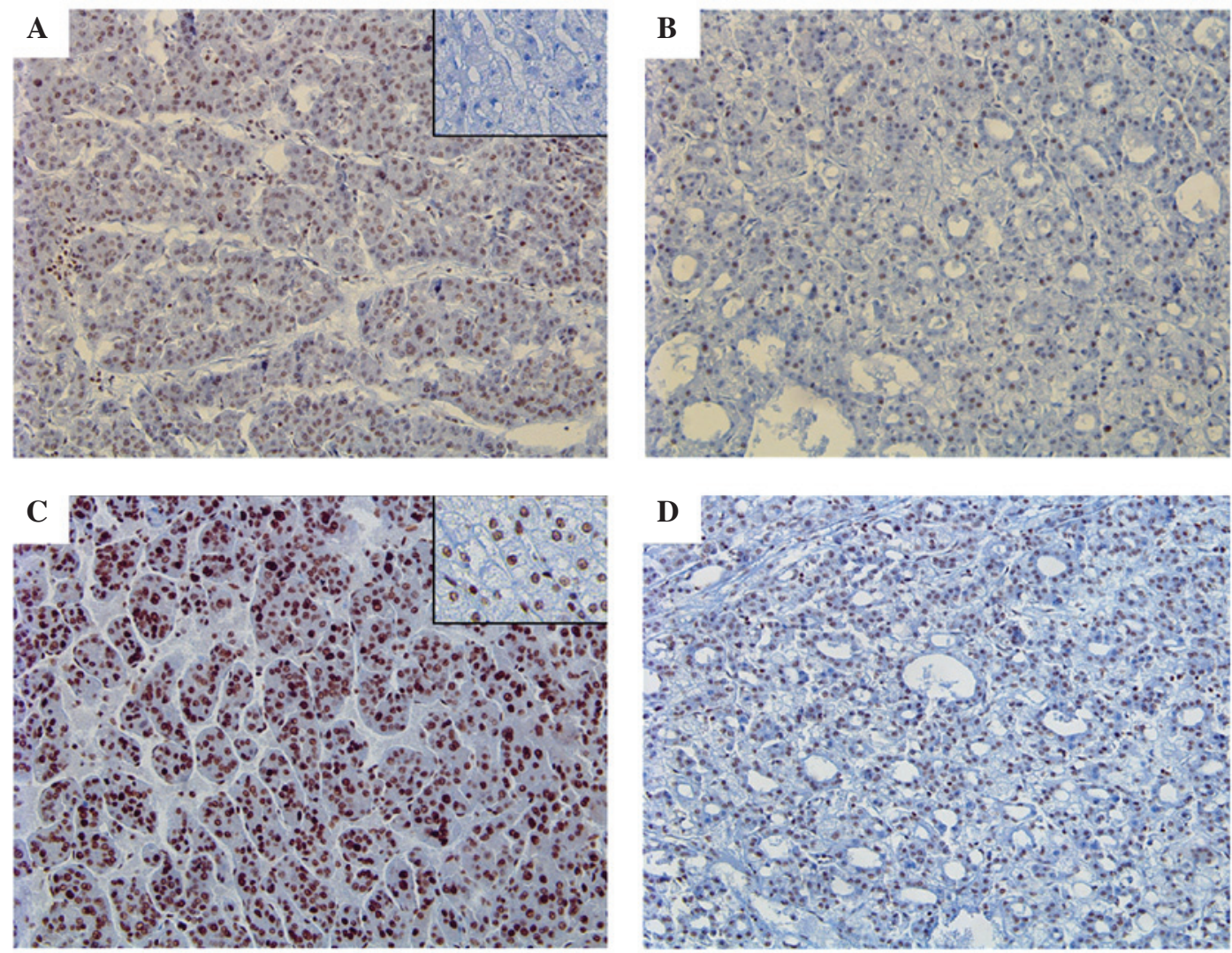

Figure 1. Expression of Gli-1 and Gli-2. Nuclear staining of Gli-1 in (A) a trabecular pattern and (B) a pseudoacinar pattern in HCC tissues, in contrast to normal liver tissue (inset of A). Strong and diffuse nuclear staining of Gli-2 in (C) a trabecular pattern and (D) a pseudoacinar pattern in HCC tissues, in comparison to adjacent normal liver parenchyme (inset of C). HCC, hepatocellular carcinoma. Magnification A-D, x20.
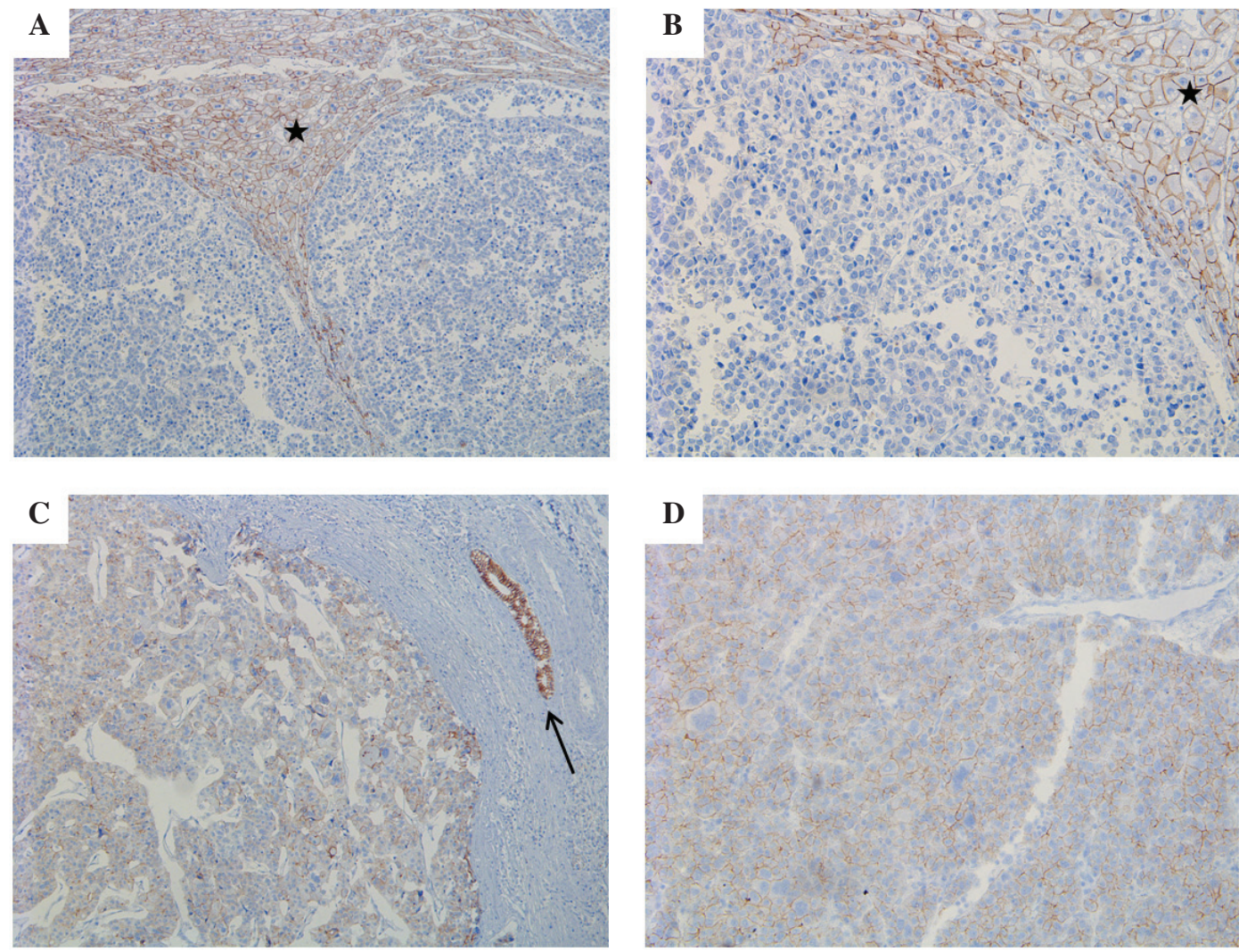

Figure 2. Expression of E-cadherin. (A) Absolute loss of E-cadherin expression in HCC tissues compared to strong and diffuse membranous staining in the adjacent normal liver parenchyme (star) (magnifiction, x10). (B) Enlarged image of (A) (magnification, x20). (C) Weakening of E-cadherin expression in HCC tissues. The adjacent bile duct is indicated by an arrow (magnification, x10). (D) Enlarged image of (C) (magnification, x20). HCC, hepatocellular carcinoma. 

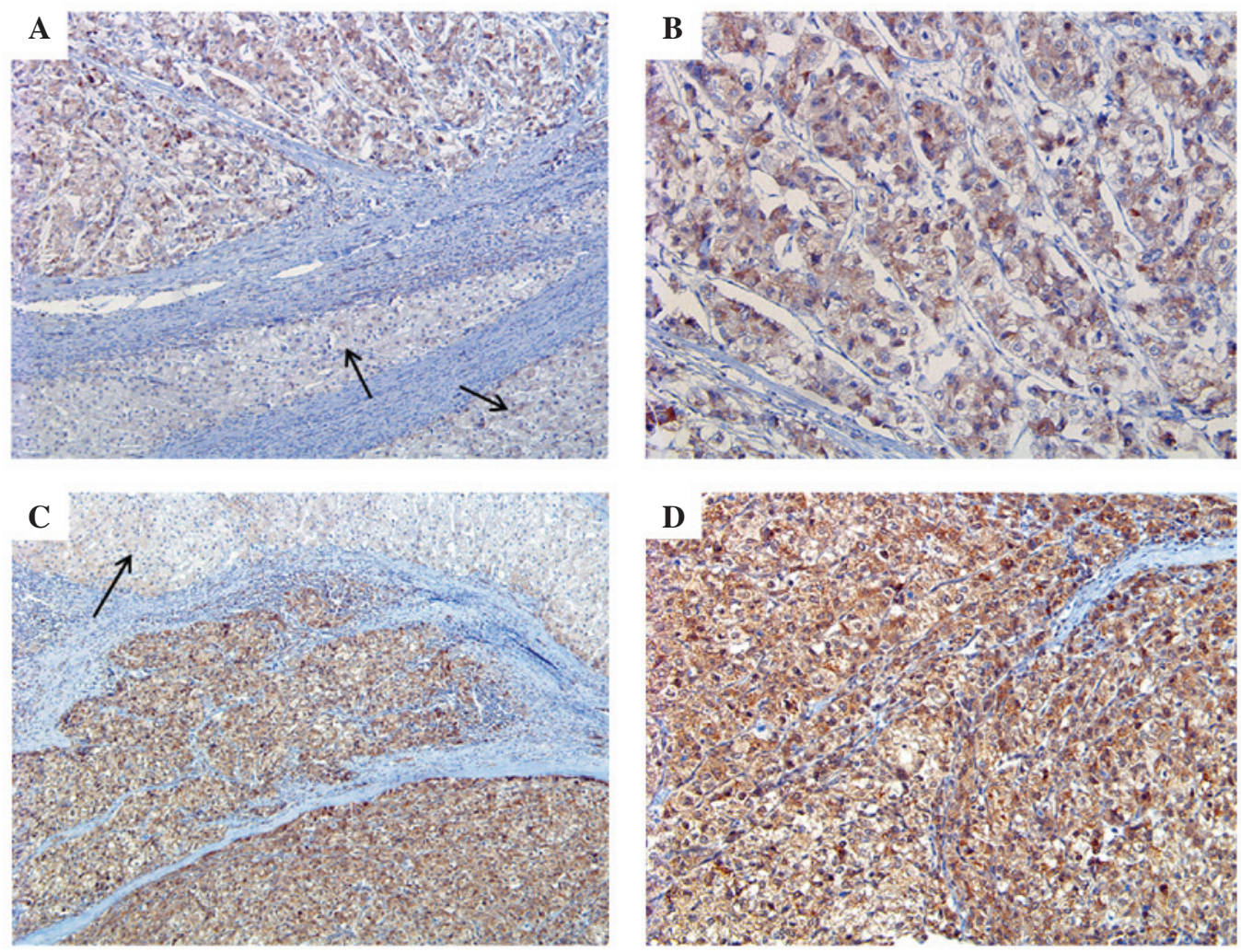

Figure 3. Expression of Twist. (A) Weak and diffuse staining of twist in HCC in contrast to adjacent normal liver tissue (arrow) (magnification, x10). (B) Enlarged image of (A) (magnification, x20). (C) Strong and diffuse staining of twist in HCC in contrast to adjacent normal liver tissue (arrow) (magnification, x10). (D) Enlarged image of (C) (magnification, x20). HCC, hepatocellular carcinoma.

pathway-associated proteins Gli-1 and Gli-2 and the EMT-associated proteins Twist and E-cadherin. However, there was no significant association identified. By contrast, E-cadherin expression showed an inverse association with Twist expression $(\mathrm{P}=0.006)$. An association between high expression of Twist and loss of E-cadherin expression has been reported in previous studies of endometrial cancer, HCC and colon cancer (39-41). The study by Lee et al (40) reported a correlation between HCC metastasis and Twist-induced HCC invasiveness through EMT by suppression of E-cadherin expression. Yang et al (22) first reported the role of Twist in cancer metastasis. This study suggested that Twist induced EMT, resulting in the promotion of tumor invasion (22). However, the role of EMT-associated proteins in cancer metastasis is controversial. Certain studies have shown that Twist overexpression is correlated with EMT-mediated metastasis in prostate and breast cancers $(22,42)$. By contrast, other studies have reported that there is no correlation between Twist overexpression and EMT-mediated metastasis in gastric and colon cancers $(43,44)$. Twist, similar to other EMT-inducing transcription factors, such as Snail, Slug and SIP, bind DNA using similar E-box sequence motifs, repressing E-cadherin expression (38). In the study of breast cancer by Fackler et al (45), Twist was hypermethylated less often in infiltrating lobular carcinoma (ILC) than in infiltrating duct carcinoma (IDC), and exhibited increased expression in IDC compared with ILC. Promoter methylation of the Twist gene has been reported in breast cancer, particularly in metastatic lesions (46). Although increasing evidence has shown the importance of Twist in the development and progression of human cancers, the underlying function is controversial. These contrasting data suggest that the role of Twist in tumor progression may be cell type-specific, and the role of Twist in cancer progression thus requires additional investigation (40).

The expression of E-cadherin is regulated at the genetic level through gene mutation, loss of heterozygosity and hypermethylation of its promoter in various cancers $(39,46)$. However, Tamura et al (47) reported that E-cadherin promoter methylation is not closely associated with the loss of E-cadherin expression. The regulatory mechanism of E-cadherin is controversial and consensus has not been reached (40).

In summary, the present study showed that expression of Gli-1, Twist and E-cadherin in HCC was significantly different compared with NTL, which suggests a diagnostic value of these proteins in HCC. In addition, increased expression of Gli-1 and Twist plays a role in the pathogenesis of HCC. Twist expression is associated with reduced expression of E-cadherin, which suggests that Twist provides tumoral invasiveness through EMT by loss of E-cadherin expression. These results may be used to inform guidelines regarding therapeutic approaches for HCC, such as the regulation of E-cadherin. The present study aimed to analyze the association between the Hh signaling pathway and EMT in HCC. However, there was no significant difference in the expression of proteins in the two groups. Additional investigation of the interaction between the Hh signaling pathway and EMT in HCC and the prognostic value of these proteins may be required. 


\section{Acknowledgements}

The present study was supported by research funds from the Institute of Medical Science, Chosun University, Republic of Korea, 2012.

\section{References}

1. El-Serag HB and Rudolph KL: Hepatocellular carcinoma: Epidemiology and molecular carcinogenesis. Gastroenterology 132 2557-2576, 2007.

2. Lau WY and Lai EC: Hepatocellular carcinoma: Current management and recent advances. Hepatobiliary Pancreat Dis Int 7: 237-257, 2008

3. Zhou YM, Cao L, Li B, Zhang RX, Sui CJ, Yin ZF and Yang JM: Clinicopathological significance of ZEB1 protein in patients with hepatocellular carcinoma. Ann Sung Oncol 19: 1700-1706, 2012.

4. Hubert C, Sempoux C, Rahier J, Horsmans Y, Geubel A, Van Beers BE, Annet L, Zech F, Leonard D and Gigot JF: Prognostic risk factors of survival after resection of hepatocellular carcinoma. Hepatogastroenterology 54: 1791-1797, 2007.

5. Sherman M: Recurrence of hepatocellular carcinoma. N Engl J Med 359: 2045-2047, 2008.

6. Zhang D, Cao L, Li Y, Lu H, Yang X and Xue P: Expression of glioma-associated oncogene 2 (Gli2) is correlated with poor prognosis in patients with hepatocellular carcinoma undergoing hepatectomy. World J Surg Oncol 29: 25, 2013.

7. Beachy PA, Karhadkar SS and Berman DM: Tissue repair and stem cell renewal in carcinogenesis. Nature 432: 324-331, 2004

8. Wicking C, Smyth I and Bale A: The hedgehog signaling pathway in tumorigenesis and development. Oncogene 18 7844-7851, 1999.

9. Berman DM, Karhadkar SS, Maitra A, Montes De Oca R, Gerstenblith MR, Briggs K, Parker AR, Shimada Y Eshleman JR, Watkins DN and Beachy PA: Widespread requirement for Hedgehog ligand stimulation in growth of digestive tract tumours. Nature 425: 846-851, 2003.

10. Ji J, Kump E, Wernli M and Erb P: Gene silencing of transcription factor Gli2 inhibits basal cell carcinomalike tumor growth in vivo. Int J Cancer 122: 50-56, 2008.

11. Kubo M, Nakamura M, Tasaki A, Yamanaka N, Nakashima H, Nomura M, Kuroki S and Katano M: Hedgehog signaling pathway is a new therapeutic target for patients with breast cancer. Cancer Res 64: 6071-6074, 2004.

12. Thayer SP, di Magliano MP, Heiser PW, Nielsen CM, Roberts DJ, Lauwers GY, Qi YP, Gysin S, Fernández-del Castillo C, Yajnik V, et al: Hedgehog is an early and late mediator of pancreatic cancer tumorigenesis. Nature 425: 851-856, 2003.

13. Thiyagarajan S, Bhatia N, Reagan-Shaw S, Cozma D, Thomas-Tikhonenko A, Ahmad N and Spiegelman VS: Role of GLI2 transcription factor in growth and tumorigenicity of prostate cells. Cancer Res 67: 10642-10646, 2007.

14. Velcheti V and Govindan R: Hedgehog signaling pathway and lung cancer. J Thorac Oncol 2: 7-10, 2007.

15. Von Hoff DD, LoRusso PM, Rudin CM, Reddy JC, Yauch RL, Tibes R, Weiss GJ, Borad MJ, Hann CL, Brahmer JR, et al: Inhibition of the hedgehog pathway in advanced basal-cell carcinoma. N Engl J Med 361: 1164-1172, 2009.

16. Gupta S, Takebe N and Lorusso P: Targeting the hedgehog pathway in cancer. Ther Adv Med Oncol 2: 237-250, 2010.

17. Katano M: Hedgehog signaling pathway as a therapeutic target in breast cancer. Cancer Lett 227: 99-104, 2005.

18. Karlstrom RO, Tyurina OV, Kawakami A, Nishioka N, Talbot WS, Sasaki H and Schier AF: Genetic analysis of zebrafish glil and gli2 reveals divergent requirements for gli genes in vertebrate development. Development 130: 1549-1564, 2003.

19. Katoh Y and Katoh M: Hedgehog signaling, epithelial-to-mesenchymal transition and miRNA (review). Int J Mol Med 22: 271-275, 2008

20. Thiery JP: Epithelial-mesenchymal transitions in tumour progression. Nat Rev Cancer 2: 442-454, 2002.

21. Mani SA, Guo W, Liao MJ, Eaton EN, Ayyanan A, Zhou AY, Brooks M, Reinhard F, Zhang CC, Shipitsin M, et al: The epithelial-mesenchymal transition generates cells with properties of stem cells. Cell 133: 704-715, 2008.
22. Yang J, Mani SA, Donaher JL, Ramaswamy S, Itzykson RA, Come C, Savagner P, Gitelman I, Richardson A and Weinberg RA: Twist, a master regulator of morphogenesis, plays an essential role in tumor metastasis. Cell 117: 927-939, 2004.

23. Wang ZS, Shen Y, Li X, Zhou CZ, Wen YG, Jin YB and Li JK: Significance and prognostic value of Gli-1 and Snail/E-cadherin expression in progressive gastric cancer. Tumour Biol 35: 1357-1363, 2014

24. Odze RD and Goldblum JR (eds): Surgical pathology of the GI tract, Liver, Biliary Tract and Pancreas. 2nd ed. Saunders, Philadelphia: p1303, 2009

25. Hashiguchi M, Ueno S, Sakoda M, Iino S, Hiwatashi K, Minami K, Ando K, Mataki Y, Maemura K, Shinchi H, et al: Clinical implication of ZEB-1 and E-cadherin expression in hepatocellular carcinoma (HCC). BMC Cancer 13: 572, 2013.

26. Dessaud E, McMahon AP and Briscoe J: Pattern formation in the vertebrate neural tube: A sonic hedgehog morphogen-regulated transcriptional network. Development 135: 2489-2503, 2008.

27. Wang ZC, Gao J, Zi SM, Yang M, Du P and Cui L: Aberrant expression of sonic hedgehog pathway in colon cancer and melanosis coli. J Dig Dis 14: 417-424, 2013.

28. Kump E, Ji J, Wernli M, Häusermann P and Erb P: Gli2 upregulates cFlip and renders basal cell carcinoma cells resistant to death ligand-mediated apoptosis. Oncogene 27: 3856-3864, 2008.

29. Eichberger T, Sander V, Schnidar H, Regl G, Kasper M, Schmid C, Plamberger S, Kaser A, Aberger F and Frischauf AM: Overlapping and distinct transcriptional regulator properties of the GLI1 and GLI2 oncogenes. Genomics 87: 616-632, 2006.

30. Im S, Choi HJ, Yoo C, Jung JH, Jeon YW, Suh YJ and Kang CS: Hedgehog related protein expression in breast cancer: Gli-2 is associated with poor overall survival. Korean J Pathol 47: $116-123,2013$

31. Karayiannakis AJ, Syrigos KN, Chatzigianni E, Papanikolaou S, Alexiou D, Kalahanis N, Rosenberg T and Bastounis E: Aberrant E-cadherin expression associated with loss of differentiation and advanced stage in human pancreatic cancer. Anticancer Res 18: 4177-4180, 1998.

32. Winter JM, Ting AH, Vilardell F, Gallmeier E, Baylin SB, Hruban RH, Kern SE and Iacobuzio-Donahue CA: Absence of E-cadherin expression distinguishes noncohesive from cohesive pancreatic cancer. Clin Cancer Res 14: 412-418, 2008.

33. Joo YE, Rew JS, Park CS and Kim SJ: Expression of E-cadherin, alpha- and beta-catenins in patients with pancreatic adenocarcinoma. Pancreatology 2: 129-137, 2002.

34. Kalluri R and Weinberg RA: The basics of epithelial-mesenchymal transition. J Clin Invest 119: 1420-1428, 2009.

35. Peinado H, Olmeda D and Cano A: Snail, Zeb and bHLH factors in tumour progression: An alliance against the epithelial phenotype? Nat Rev Cancer 7: 415-428, 2007.

36. Zeisberg M and Neilson EG: Biomarkers for epithelial-mesenchymal transitions. J Clin Invest 119: 1429-1437, 2009.

37. Castanon I and Baylies MK: A Twist in fate: Evolutionary comparison of Twist structure and function. Gene 287: 11-22, 2002.

38. Nieto MA: The snail superfamily of zinc-finger transcription factors. Nat Rev Mol Cell Biol 3: 155-166, 2002.

39. Kyo S, Sakaguchi J, Ohno S, Mizumoto Y, Maida Y, Hashimoto M, Nakamura M, Takakura M, Nakajima M, Masutomi K and Inoue M: High Twist expression is involved in infiltrative endometrial cancer and affects patient survival. Hum Pathol 37: 431-438, 2006.

40. Lee TK, Poon RT, Yuen AP, Ling MT, Kwok WK, Wang XH, Wong YC, Guan XY, Man K, Chau KL and Fan ST: Twist overexpression correlates with hepatocellular carcinoma metastasis through induction of epithelial-mesenchymal transition. Clin Cancer Res 12: 5369-5376, 2006.

41. Ran Hong and Sung-Chul Lim: Overexpression of Twist in colorectal adenocarcinoma. Basic and Applied Pathology 2: 15-20, 2009

42. Kwok WK, Ling MT, Lee TW, Lau TC, Zhou C, Zhang X, Chua CW, Chan KW, Chan FL, Glackin C, et al: Up-regulation of Twist in prostate cancer and its implication as a therapeutic target. Cancer Res 65: 5153-5162, 2005.

43. Rosivatz E, Becker I, Specht K, Fricke E, Luber B, Busch R, Höfler $\mathrm{H}$ and Becker KF: Differential expression of the epithelial-mesenchymal transition regulators snail, SIP1, and twist in gastric cancer. Am J Pathol 161: 1881-1891, 2002. 
44. Rosivatz E, Becker I, Bamba M, Schott C, Diebold J, Mayr D, Höfler $\mathrm{H}$ and Becker KF: Neoexpression of N-cadherin in E-cadherin positive colon cancers. Int J Cancer 111: 711-719, 2004.

45. Fackler MJ, McVeigh M, Evron E, Garrett E, Mehrotra J, Polyak K, Sukumar S and Argani P: DNA methylation of RASSF1A, HIN-1, RAR-beta, Cyclin D2 and Twist in in situ and invasive lobular breast carcinoma. Int J Cancer 107: 970-975, 2003.
46. Mehrotra J, Vali M, McVeigh M, Kominsky SL, Fackler MJ, Lahti-Domenici J, Polyak K and Sacchi N: Very high frequency of hypermethylated genes in breast cancer metastasis to the bone, brain and lung. Clin Cancer Res 10: 3104-3109, 2004.

47. Tamura G, Yin J, Wang S, Fleisher AS, Zou T, Abraham JM, Kong D, Smolinski KN, Wilson KT, James SP, et al: E-Cadherin gene promoter hypermethylation in rimary human gastric carcinomas. J Natl Cancer Inst 92: 569-573, 2000. 